\title{
10
}

\section{Purpose and Social Inclusion}

Social exclusion contributes to loneliness and social isolation. Both have profound psychological and physical implications in older individuals that adversely affect their quality of life. ${ }^{1,2,3}$ Loneliness is associated with increased mortality and functional limitation ${ }^{4,5,6,7,8}$ and has been linked to increased rates of depression. ${ }^{9}$ Loneliness and social isolation are challenges faced by societies around the world. ${ }^{10,11,12,13}$

Social inclusion is a core component of optimal aging. Retirement, the loss of a spouse or friends, children living far away, the inability to drive, and physical or cognitive limitations all increase the risk of loneliness in older adults. Those with chronic illness are sometimes prone to selfisolation to avoid the stigma associated with aging, illness, and dementia. ${ }^{14}$ Public spaces that are not welcoming and accessible to those who are older, ill, or have cognitive limitations contribute to social isolation. In advanced age, people seek meaning and purpose. They often wish to leave a legacy to the generations that follow their own. Intergenerational connections can fill this need and foster community connection and inclusion. Intergenerational connections are beneficial for society as a whole because they challenge ageist beliefs. ${ }^{15,16}$ Such connections also offer older adults the opportunity to fulfill their need for purpose and 
generativity. ${ }^{17}$ Having a purpose contributes to psychological and physical well-being. ${ }^{18,19,20}$ Another trend that often leads to intergenerational connections, social inclusion, and purpose is lifelong learning.

The profound effects of loneliness on health and independence are a critical public health problem. It is no longer medically or ethically acceptable to ignore older adults who feel lonely and marginalized. ${ }^{21}$ (Dr. Carla M. Perissinotto, MD, MHS geriatrician, University of California, San Francisco)

\section{Lifelong Learning}

Increased lifespans have led to many more years of retirement. Those added retirement years are perfect opportunities for adult education, a trend that is taking place around the world. Some governments are recognizing the need for adult learning and training to support a shrinking workforce. ${ }^{22}$ The population of working-age people in China is projected to decline by one third by $2050 .{ }^{23}$ Today, China has 60,000 universities for older adults with 7 million students enrolled. The country plans to expand universities for older adults to include one in every city. ${ }^{24}$ The Chinese government believes that the universities keep older adults socially engaged, out of old-age homes, and potentially active in the workforce. ${ }^{25}$

The universities for seniors are in higher demand now because many newly retired are better educated. They are not satisfied with just playing mahjong or gossiping with their friends. ${ }^{26}$ (Xiong Fangjie, Vice President of Shanghai University for the Elderly)

Lifelong learning offers older adults the opportunity to learn new information and build a new career, improve health management, enjoy creative studies, or explore other subjects they have always been interested in but did not have the time to pursue until their retirement years. Demand has driven many of the accredited, degree-granting colleges in the United States to offer greatly reduced or free tuition to those 65 and older. ${ }^{27}$ Lifelong learning has shown to contribute to general well-being, life sat- 
isfaction, and intellectual, social, physical, emotional, and occupational wellness. ${ }^{28,29}$

\section{United Nations Principles for Older Persons}

In 1991, the United Nations issued the Principles for Older Persons that encouraged governments of member states to integrate five principles into their policies and programs. ${ }^{30}$ All of the principles support social inclusion and optimal aging. The summarized principles are that older people should have:

- Independence, including the ability to age in place, employment opportunities, access to educational programs, and safe and supportive environments that are adapted to their capacities;

- Participation, including active participation in society and the ability to fulfill their need for generativity ${ }^{31}$;

- Care, including the benefit of family and community support, and to be involved in their own care planning;

- Self-fulfillment, including access to education, culture, recreation, and spiritual resources;

- Dignity, including being treated with respect and being valued by society.

This chapter describes housing and community models and interventions that support the principles outlined by United Nation.

\section{Housing}

Housing and community are important factors that can help to keep older adults socially and civically engaged. As governments seek sustainable housing options for their older residents, the focus is often on enabling aging in place because living at home is far less expensive than living in independent or assisted living communities. Two community models developed organically in the United States driven by residents who had aged together 
and wished to stay in their homes and connected to their community. These models integrate healthcare and social services with housing and community. They also have a strong social component.

We wanted to be active and taking care of ourselves and each other rather than being taken care of. (Beacon Hill Village ${ }^{32}$ )

\section{The Village Movement}

The Village Movement began in 2002 in Beacon Hill, Boston. ${ }^{33}$ The Village concept was born out of residents' desire to remain connected to their community as they aged. Villages are member-run, self-supporting grassroots organizations. The Village hires staff to oversee the collective delivery of health, social, and other services that make it possible for the members to remain in their community. Many Village members, who are independent and still working, join their local Village for the robust social activities that are individualized to the community.

Because of their size, the Village community has leveraging power on prices. Members receive discounts including:

- Gym membership, classes, and trainers;

- Drivers (rides to doctor prescribed visits are free);

- Computer help offered free of charge by volunteers or for a discounted rate by professionals;

- Handyman;

- Home health assistance;

- Companions;

- Cooking classes;

- Social programs.

The Village members engage in community activities and social events including:

- Cultural arts excursions;

- Talks by local experts about cultural, political, health and wellness, and memory topics; 
- Lunches, coffees, cocktail parties, and special interest groups;

- Day trips to local attractions. ${ }^{34}$

Villages are financially accessible to many because fees are considerably less expensive than moving to independent and assisted living communities. The national average for a private one bedroom in assisted living is US $\$ 3628$ per month. ${ }^{35}$ A one bedroom in independent living varies from state to state, ranging from US\$1399.00 in South Dakota to US\$4002.00 in Massachusetts. ${ }^{36}$ A Beacon Hill Village monthly membership costs US\$675 for an individual and US\$976 for a household. Discounted monthly memberships are available to lower- and moderate-income individuals who are 60 and older. Those monthly fees range from US\$110 for an individual to US\$160 for a household. Members who join only for the social activities pay approximately US $\$ 250$ per month for a household. ${ }^{37}$

The Beacon Hill Village has approximately 400 members who are 50 and over who live in Beacon Hill, Back Bay, North End, South End, and surrounding neighborhoods. The Beacon Hill Village members were inspired to create the Village to Village Network to exchange ideas and new tools with the other villages around the country and the world. ${ }^{38}$ Villages promote active, productive community engagement and autonomy for the residents. A slightly different housing model that promotes the same community qualities is the naturally occurring retirement community.

\section{Naturally Occurring Retirement Communities}

The first naturally occurring retirement community (NORC) began in 1986 in New York City. NORCs vary. They can be situated in subsidized housing complexes, neighborhoods with private homes, condominiums and cooperatives, and rental apartment buildings. In these communities, most residents moved in at a younger age, raised their children, and continued to stay in their homes and age together. Specifications for NORCs have continued to change over time, but approximately 40 percent or more of the residents in NORCs are over 60.

With governmental and philanthropic funding, public and private community-based organizations collaborate in the NORC Supportive 
Service Program (NORC-SSP) to deliver services to the community members including: healthcare, health promotion and prevention, psychological support, social and educational activities, and social services, including meals. This proactive population health service delivery is possible because the older adults reside in concentrated locations. NORC residents actively participate in needs assessments and program planning with building owners, housing managers, local businesses, local law enforcement, and civic, religious, and cultural institutions to shape an inclusive community that enables them to live in their homes as they age. The number of NORCs has risen along with the growth in the aging population. As of 2012 there were 315 NORCs in the world and 50,000 older adults living in more than 40 NORCs in New York State alone. ${ }^{39}$

\section{JDC-ESHEL}

JDC-ESHEL is a model similar to the NORC-SSP that has existed in Israel for the past 45 years. The US-based non-governmental organization, the Joint Distribution Committee (JDC), and ESHEL coordinate with public and private entities to deliver services to older community residents. The model gives seniors the option to remain living at home and connected to their social circle rather than move into expensive institutional residences. Some have claimed that JDC-ESHEL provides a "multiplier effect throughout the entire health and social services sectors." 40

Another housing model that is based in the culture of social engagement, intergenerational connections, and community and civic engagement is cohousing.

\section{Cohousing}

Israel has a 100-year-old country-specific version of cohousing called kibbutzim. Kibbutz are home to 120,000 Israelis. ${ }^{41}$ The cohousing model we will describe, Bofaellesskaber, began with the community, Skråplanet in Denmark in 1964, inspired by the publication of The Missing Link Between Utopia and the Dated One Family House, by architect Jan Gudmand- 
Hoyer. The model eventually spread to countries around the world. Today there are approximately 700 cohousing communities in Denmark. In the United States, there are 165 established cohousing communities and another 304 in varying stages of completion and occupancy. ${ }^{42}$

Cohousing communities are often referred to as intentional collaborative neighborhoods. The communities are founded on mutual support between the residents who wish to live in close contact with their neighbors and share occasional meals, enjoy common spaces, participate in common activities, and help each other when a need arises. Cohousing communities are naturally multigenerational with the exception of senior-only cohousing communities.

Common characteristics of a cohousing community include:

- Decisions are made by a consensus of community members;

- Communities contain a balance of private homes and community spaces;

- Structures are designed to promote interaction and connection;

- Residents care for each other.

A central design element of cohousing communities is the common house that contains a kitchen, dining room/event space, and other public spaces such as a laundry room, guest room, gym, and play room for children. Residents use the common kitchen to cook meals that are shared with the cohousing community at varying intervals, depending on the community. Cooking responsibilities rotate and the residents each contribute to the cost of the shared meals.

Cohousing community structures are designed so that residents will connect with each other. In the private homes, it is common to have a window above the kitchen sink that faces outdoor areas where neighbors pass by. Parking spaces are separate from the housing areas, so when people park, they naturally walk through the community.

In 2012, cohousing residents reported positive outcomes of living in intentional neighborhoods including:

- $96 \%$ had increased satisfaction with life as a result of living in cohousing; 
- $75 \%$ felt that they were experiencing better health than others in their age group;

- $96 \%$ had voted in the last presidential election. ${ }^{43}$

The overarching characteristic of cohousing is that we know our neighbors well. (Joani Blank)

\section{Joani Blank, Cohousing Enthusiast and Resident}

Joani Blank has lived in cohousing since 1991. At the time of the interview she lived in the Swan's Market Cohousing community in Oakland, California. At the time of the interview, Joani was 78 years old. Since our meeting, Joani passed away to the disappointment of the community that embraced her. Her daughter, son in law, and their newborn baby now live in Joani's former home and are bringing three new young residents to the Swan's Market community.

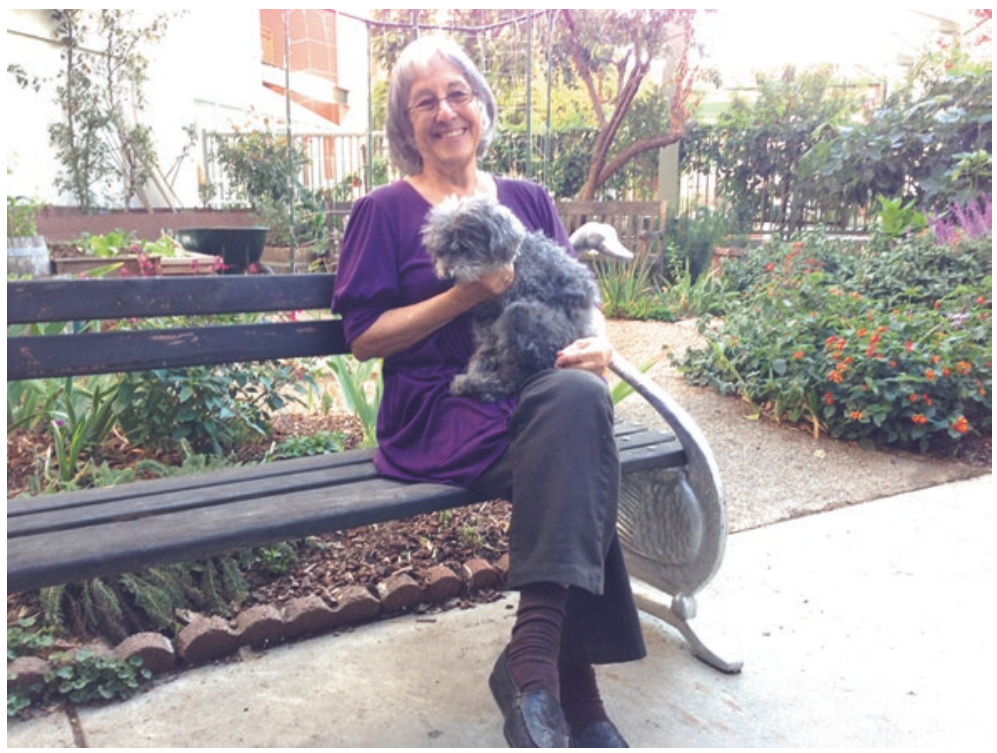

Joani Blank in front of the Swan's Market Cohousing community garden 
It is common for future residents to participate in designing new cohousing communities. This process is called participatory or cooperative design ${ }^{44}$ Joani explained that the first 11 residents of the Swan's Market cohousing community participated in the design and planning of the structure over a five-year period. The cohousing community sits within a larger commercial space that includes restaurants, shops, art galleries, and apartments. ${ }^{45}$ The residents also have convenient access to other amenities in the bustling city of Oakland, California.

Joani explained that cohousing communities have some common features, but each community is personalized to the residents. One community that Joani visited had a library in the common house because two retired librarians lived in the community. The library was used regularly by residents of all ages, and the librarians took pleasure in managing and promoting it.

The ideology of cohousing is really about creating neighborhood in a new way.

Joani shared her feelings that regular social engagement with her neighbors is possible without compromising the need for privacy. She mentioned that as America has grown, communities have become spread out with large lawns and fences separating one home from the other. Even in urban areas with multifamily buildings, often the residents do not form supportive relationships with each other.

\section{Shared Meals}

The residents in cohousing partake in shared meals. In Swan's Market cohousing, they share three common meals each week. Two residents prepare the meals together. Meal preparation is generally looked upon as a fun opportunity to try new recipes. With that schedule, each resident is required to make dinner only once every four and a half weeks. This is convenient for everyone, but especially so for older people who may not want the burden of dinner preparation and do not wish to dine alone. The average cost to enjoy a prepared meal at Swan's Market cohousing is US\$4.75. 
When anything needs doing, we do it together. That is the way you do things in a community.

\section{Shared Decisions and Projects}

Cohousing residents make decisions about the operation and maintenance of the community collectively. The residents of the Swan's Market formed committees including finance, garden, group process, common house, maintenance, external relations, technology, and social. The committees also oversee the group workdays and special building and grounds maintenance projects.

\section{Intergenerational Connections}

At the time of our interview, the Swan's Market cohousing community was home to 28 adults; one college student, one teenager, and a toddler. Joani shared that the multigenerational nature of cohousing is beneficial for all the residents. Parents, especially single parents, receive much support from the other residents. Children who have grandparents living far away live next door to older people who have the time and interest in forming grandparent-type relationships. Joani's grandchildren are older and live far away. It makes her happy to care for the toddler who lives three doors away. The younger people are willing to go up on a ladder for older residents who are no longer comfortable with that and other tasks. Joani also mentioned that the younger generations are willing and able to help their fellow older residents with technology.

Independent and assisted living residences also have the ability to build intergenerational connections, inclusive communities, and lifelong learning. We described the models of person-centered long-term care of St. Johns and Beatitudes previously in Chap. 2. Here, we wish to highlight their programs that create purposeful connections between residents and the local community. 


\section{Rebecca Priest, Administrator of Skilled Nursing, St. John's}

Rebecca Priest is the Administrator of Skilled Nursing at St. John's Home. Rochester, New York-based St. John's is a full-spectrum senior services provider with four home- and village-like campuses.

St. John's long-term care has a privately operated day care on campus and the children visit the residents daily. They also engage in programs with the residents such as building snowmen in the courtyard in winter and participating in planting events in the spring. ${ }^{46}$

St. John's has a long-standing practice of residents participating in intergenerational courses at the St. John Fisher College. In autumn of 2016, a group of ten residents from St. John's Meadows and Brickstone by St. John's joined in the "Campaigns and Elections" class discussion several times throughout the semester. According to professor, Dr. Kathleen Donovan, having residents join the class led to a more informed conversation on politics. "For many students, this was the first election they have paid any attention to, so they have no reference point. Having citizens who have experienced elections as an adult is incredibly helpful."

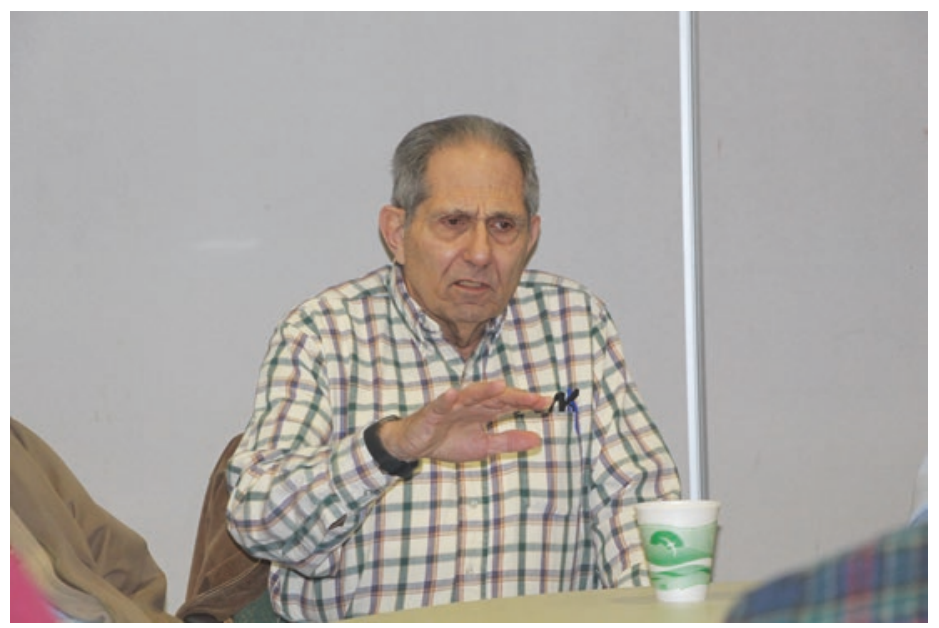

St. John's resident Larry Nazarian discusses his military experience with fellow residents and St. John Fisher College students as part of the Dialogues on War program, an intergenerational learning initiative 
St. John's Collaborative for Intergenerational Learning is an educational program for Nazareth College students and residents from St. John's. At the beginning of each semester, a group of residents from St. John's Meadows and Brickstone by St. John's join a class of Nazareth students to describe the aging process from their perspective. Many of the Nazareth College students are studying to become physical, occupational, and speech therapists. The collaborative helps future clinicians understand the patients they will be interacting with throughout their careers.

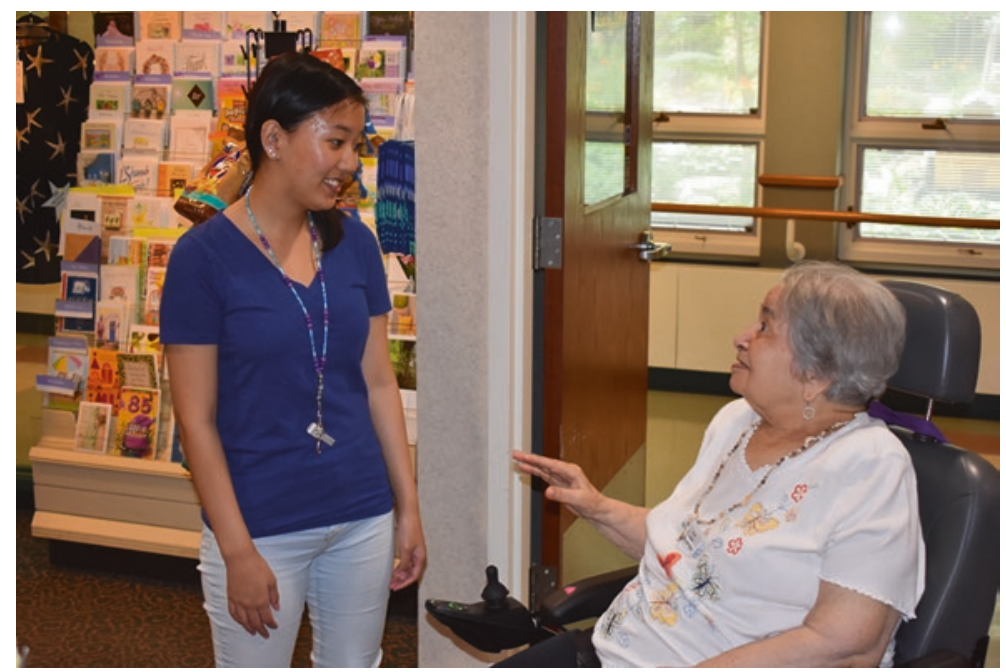

St. John's Home gift shop volunteer Leah Cocilova visits with resident and fellow volunteer Anne Giglia

St. John's Meadows and Brickstone by St. John's independent living campuses have a continual stream of social activities that are run, established, or inspired by the residents. ${ }^{47,48}$ The Brickstone campus has meeting spaces, restaurants, and other businesses that are open to the public. These promote meaningful social connections with the residents' peers and younger community members. Beatitudes Campus is another example of senior living that is continually abuzz with resident activities and events. ${ }^{49}$

Our campus is based on purposeful living. (Tena Alonzo) 


\section{Tena Alonzo, Karen Mitchell, and Ivan Hilton, Beatitudes Campus}

Tena Alonzo is the Director of Education and Research and the Director of the Comfort Matters ${ }^{\mathrm{TM}}$ program at Beatitudes Campus. ${ }^{50}$ Karen Mitchell is an Educator of Comfort Matters ${ }^{\text {TM }} .{ }^{51}$ Ivan Hilton is the Director of Business Development for Comfort Matters ${ }^{\mathrm{TM}}$. Phoenix, Arizona-based Beatitudes Campus is a life plan community (sometimes referred to as a continuing care retirement community) with 700 residents.

Beatitudes Campus partners with local schools for the students to visit the campus as part of their service project requirement. One student is honored monthly and the campus residents are the competition judges. Some of the Beatitudes campus residents contribute to scholarships for local high school students that are presented at a banquet at the end of the school year. There are many residents who are former teachers and education is still their mission.

We are a life plan community without walls.

Beatitudes has 97 clubs and meetings that were started by and are run by residents. Many in the baby boomer generation were civically active throughout their lives and are leading clubs at Beatitudes to continue their civic engagement. One group, Seniors for a Sustainable Future, traveled to Washington, DC, to lobby.

Some of the Beatitudes residents feel a dedication to the lesbian, gay, bisexual, and transgender (LGBT) community in Phoenix. They began a LGBT support group for campus residents and the Phoenix community. The group meets weekly and has 150 members.

Beatitudes also hosts activities of many outside organizations that are open to the residents. Community members of all ages can enjoy a meal in the campus restaurants and bars that are open to the public. Beatitudes hosts a weekly concert called a Hootenanny that is organized by Igor Glen, a resident who is a professional musician. Musicians who are residents play along with local community members and Igor Glen. 
Lasell Village is also a hub of intergenerational connections and social activities, but what makes the Village even more unique is that it takes lifelong learning a step further than other life plan, or continuing care retirement communities.

\section{Anne Doyle, Lasell Village}

Anne Doyle is the Vice President of Lasell College and the President of Lasell Village, a life plan community that is on the campus of Lasell College in Newton, Massachusetts. ${ }^{52}$

As the name connotes, Lasell Village is designed like a small village that is comprised of 16 buildings that resemble townhouses. Each building has common areas such as living rooms, courtyards, libraries, classrooms, and meeting rooms. Other amenities include gardens, a swimming pool, a gym, restaurants, a bank, a day care, and a preschool. The demographic profile of the Village resembles that of most life plan communities in the United States with residents ranging from 72 to 103 , with an average age of 80 .

Lasell Village is home to 225 adults who are committed to lifelong learning. Part of the admissions contract is the requirement for residents to participate in 450 hours of learning annually. At first glance this seems like a rigorous requirement, but Anne Doyle reported that last year the residents averaged 550 hours per resident. Anne estimates that the actual number is higher because, after residents have met the required hours, many discontinue documenting their learning time.

The courses are continually changing and evolving in response to feedback from the residents and the college. No idea or suggestion is turned away.

All classes at Lasell College are free to the Village residents. This presents the opportunity for regular intergenerational contact. The Intergenerational Educational Program group, including the Associate Dean of education at the college, a faculty member, a college student, the head of the Fuss Center for Intergenerational Research and Aging, ${ }^{53}$ Anne Doyle, and two Village staff members plan educational programming 
based on the feedback and request of the students and residents. Intergenerational course modules are designed around existing course content and involve more classroom exchange. In these modules, students, young and old, benefit from insights and ideas shared by different generations. Occasionally residents teach courses based in the expertise they have acquired during their lifetimes. Many students from Lasell College work at the Village and build relationships with the residents out of the classroom also.

The relationship between residents and traditional college students often become an informal mentor relationship, which has deep meaning for both.

Anne described the special juxtaposition that exists between the residents of Lasell Village and the students of Lasell College. The Village residents generally have $\mathrm{PhDs}$, MDs, and a host of other academic degrees, while 46 percent of the students have parents who have not completed college. Anne mentioned that the residents take an interest in the success of the students and provide support and encouragement. Some residents help the students with the financial costs of college.

We are all human beings, no matter our age. We want to stay as engaged as long as we possibly can.

Residents of all physical and cognitive abilities and age are supported in their desire to participate in any classes or activities. Anne noted that, in most life plan communities, the residents living in skilled nursing are segregated from the community, as are those living with cognitive challenges. She mentioned one gentleman who lives in skilled nursing who participates in every rehearsal of the Village chorus, Voices of Experience. ${ }^{54}$ The same resident also takes educational courses.

The Village is regularly bustling with intergenerational activity. The preschool and nursery school children can be seen all around the campus as part of their daily activities. They interact with the residents just as children in a village would. On any given day, you can find a resident reading to one of the preschool children in the courtyard or library. You can also hear the children's chorus echoing through the halls. Many of the 
residents who are retired teachers volunteer at the nursery and preschool and others volunteer at an elementary school just down the street.

Some of the Lasell Village residents continue with their active career lives. Anne collaborates with the State Office of Elder Affairs to create internship positions for residents of the Village who are eager to contribute a stakeholder's perspective.

We have written about examples of residential and institutional housing that is inclusive and supportive of optimal aging. City design and policy that is structured with input by the older residents and that involves multiple sectors can also support optimal aging. Cities that are inclusive to those of all ages and abilities empower people to remain in the workforce if they wish, participate in purposeful activities, and remain respected pillars of their community.

Cities are hubs of creativity, business, social connection, and diversity. They make the culture of a given time and place. It is therefore critical that all are able to participate in the vibrant life of the city. Reconceptualization of key physical and social design features is necessary to gain the full benefit of the contributions older adults bring. (Ruth Finkelstein, former Associate Director of the Robert N. Butler Columbia Aging Center)

\section{Age-Inclusive Cities}

Age-inclusive cities, also referred to as age-friendly cities, benefit all generations and strengthen the fabric of society as a whole. The World Health Organization identified eight domains that make a community agefriendly. ${ }^{55}$ Those domains are:

1. Outdoor spaces and buildings, including parks, sidewalks, safe streets, outdoor seating, and buildings that are safe and accessible to people of all physical abilities;

2. Transportation, including age-accessible public transportation;

3. Housing, including affordable housing options and homes that are designed or modified so older individuals can age in place;

4. Social participation, including enjoyable activities that are accessible and affordable to the older population; 
5. Respect and social inclusion, including intergenerational connections;

6. Civic participation and employment, including volunteer and paid work opportunities;

7. Communication and information, including access to information through a variety of channels because not everyone has a smart phone;

8. Community support and health services including access to health and social services in the home and community.

In 2014 the Milken Institute Center for the Future of Aging launched the Mayor's Pledge that calls for mayors and other civic leaders to create age-inclusive cities. ${ }^{56}$ The institute remains a champion for age-inclusive cities with their annual publication of "Best Cities for Successful Aging" that documents how well cities throughout the United States enable their older residents to live safe, purposeful, and healthy lives. ${ }^{57}$

Do not design for me, design with me. (June M. Fisher, MD, ${ }^{58} \mathrm{dHealth}$ Summit, 2017)

\section{Stakeholder Involvement}

It is vital to involve older adults in planning and designing age-inclusive communities. Far too often, ageism and prejudice lead private organizations, city planners, and policy makers away from soliciting the invaluable insights of the older residents they serve. The AdvantAge Assessment was designed to ascertain the level of age-friendliness of a community by surveying the community's older residents.

\section{Mia Oberlink, the AdvantAge Initiative}

Mia Oberlink is a senior research associate at the Center for Home Care Policy and Research. She manages the AdvantAge Initiative. ${ }^{59}$

The AdvantAge Initiative survey measures 33 indicators (Appendix) of age-friendliness that fall within four domains including addressing basic needs, promoting social and civic engagement, optimizing health and 


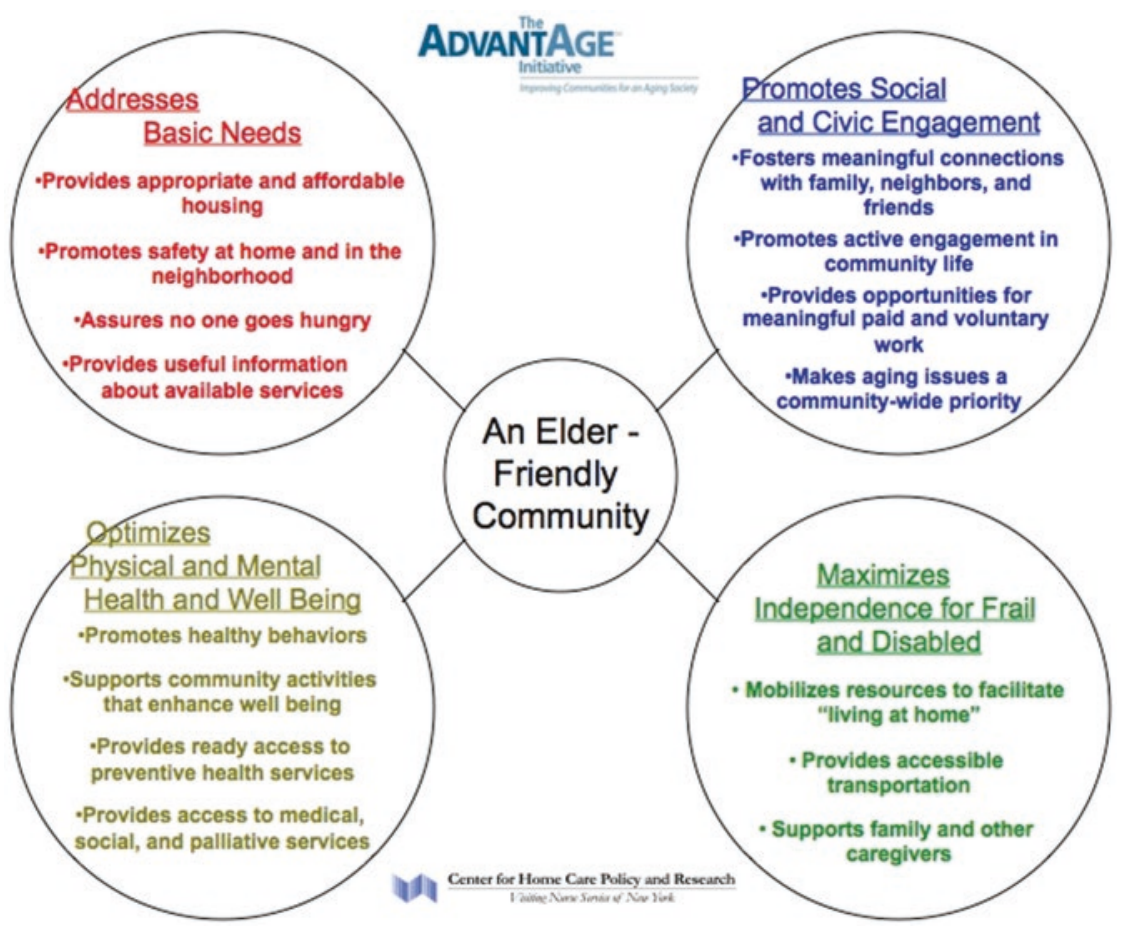

Fig. 10.1 AdvantAge Initiative. Age-friendly Measures

well-being, and maximizing independence for the frail and disabled (Fig. 10.1). When a community wishes to become age-inclusive, they contract Mia and her team to distribute the AdvantAge Initiative survey to the residents and develop strategies that address the specific needs revealed by the surveys. The goal of the AdvantAge initiative is to support the independence of the residents and to empower them to age in place while remaining productive members of the community.

Although there is census and local health department data on older adults available, one of the factors that is often missing is the input, experiences, and perceptions of the residents themselves.

Mia Oberlink mentioned that the survey regularly reveals common issues including falls, access to mental health support, access to food, and 
the desire for more social activities. Each community also presents individualized challenges. Mia and her team engage residents, local community partners, and city government to respond to the challenges. The response might be health or fall prevention interventions, adjusting traffic lights or adding a middle island so older adults can cross streets more safely, organizing meal delivery, and repairing uneven sidewalks. The initiatives that are designed for the specific needs of the neighborhood would not be possible without the input of the older residents.

Another initiative that was born from information solicited directly from older New Yorkers is the Age Smart Employer Initiative. In her former position with Age-Friendly NYC, Ruth Finkelstein conducted community needs assessments in town hall meetings around New York City to listen to the concerns of older residents. At the end of the town halls, a line of people would form to speak with Ruth. Much to her surprise, most of them wanted help in finding employment. Inspired by this experience, Ruth founded the Age Smart Employer initiative. ${ }^{60}$

\section{Ruth Finkelstein, Age Smart Employer and Exceeding Expectations Initiatives}

Ruth Finkelstein was formerly the Assistant Professor of Health Policy and Management, Associate Director of the Robert N. Butler Columbia Aging Center. Today she is the Executive Director of the Brookdale Center of Healthy Aging at Hunter College and Professor of Urban Public Health.

It is not good for most people to have a 20 -year vacation. Financing a 20-year retirement from forty years of employment simply is not affordable. It is not all about the economics either. People have a need to stay active and engaged in a meaningful life with purpose.

\section{Older Workers}

People are living longer, but policy, practice, and culture have not adapted to meet the demand of older workers who need or wish to keep working past the standard retirement age. In her interview, Ruth mentioned that 
when Social Security became law in the United States in 1935, the life expectancy was 61 and the retirement age was 65 . Today life expectancy is 83 , and the retirement age has remained unchanged. A survey by the Employee Research Institute showed that 90 percent of retirees who obtained paid employment post-retirement did so because they wanted to stay active and involved, and 82 percent reported that they enjoyed working. ${ }^{61}$

Many seniors are not financially prepared for retirement. ${ }^{62,63}$ In fact, one in three Americans have nothing saved toward retirement ${ }^{64}$ and over a quarter of the workers 55 and older report having less than US $\$ 10,000.00$ in savings and investments. ${ }^{65} \mathrm{~A}$ lack of money to spend as consumers can contribute to isolation. ${ }^{66}$ Working an additional year can increase retirement income by 9 percent and working five more years can increase it by 56 percent. ${ }^{67}$ Lower-income workers benefit even more from working longer; their retirement realizes a 16 percent increase with one more year of work and a 98 percent increase with an additional five years of work. ${ }^{68}$ We should note that the myth that older workers who delay retirement take jobs from younger workers is just that. Due to the size of the baby boom population, the number of those retiring leave more job openings per young person than existed in $1990 .{ }^{69}$ This situation exists around the globe and is leading to workforce shortages in many countries. ${ }^{70}$ Ruth pointed out that there are 700,000 workers in New York City who are over the age of 50. Many wish to remain in the workforce into their older years.

Retaining seasoned employees is a matter of good economics and good business.

Age Smart Employer is an initiative of the Robert N. Butler Columbia Aging Center that recognizes employers who exemplify best practice in retaining and attracting older employees. ${ }^{71}$ Best practice includes: opportunity for phased or part-time retirement, supporting physical limitations, understanding the value of older mentors, presenting opportunities for upward mobility, offering training or continued education, restruc- 
turing jobs, and a culture that is steeped in valuing people of all generations. The initiative involves a competition and awards ceremony that garners national attention. Past winners include many small employers that make op the heart of New York City and larger employers including NYU Langone Medical Center and Brooks Brothers. The awards shine a spotlight on employers who are reaping the benefits of their older workforce.

Often, aging is treated as a disease, rather than an opportunity to offer society expertise and wisdom in work, volunteerism, civic engagement, and education.

\section{Ageism}

Robert Butler classified ageism as a serious form of bigotry that is often overlooked. ${ }^{72}$ Ageism is fed by prejudicial stereotyping of older adults that leads to discrimination and stigmatization. It can infiltrate policies and practices of businesses, healthcare providers, city and state planning boards, local culture, and society as a whole. Ageism and negative aging stereotypes contribute to social isolation, segregation, and cognitive, psychological, and behavioral decline in older adults. ${ }^{73}$

What does eighty plus look like today? Very much alive and thriving.

Ruth Finkelstein and journalist, Dorian Block, lead the Exceeding Expectations initiative. ${ }^{74}$ Exceeding Expectations challenges ageism and the stigma of aging by profiling selected residents of New York City who have lived longer than the average life expectancy of New Yorkers, which is 81 . The videos are powerful and touchingly intimate portrayals of vibrant people living active purposeful lives.

City design and policy that support inclusion for those of all ages and abilities challenge aging stereotypes by enabling older residents to remain included and connected to their community. In 2010 New York became 
the first member of the World Health Organization's Global Network of Age-Friendly Cities.

Older people are often among the most civically engaged. They add stability and substantial social, intellectual, and financial capital to the community. (Lindsay Goldman)

\section{Lindsay Goldman, Age-Friendly NYC ${ }^{75}$}

Lindsay Goldman directs the New York Academy of Medicine in its efforts toward healthy aging.

Age-Friendly NYC is a partnership between the Office of the Mayor, the New York City Council, and the New York Academy of Medicine that works to identify and catalyze improvements to enable older people to access, enjoy, and contribute to city life. Age-Friendly NYC asks older New Yorkers about their daily lives and develops strategies to reduce or eliminate barriers to optimal social, physical, and economic participation.

Age-Friendly NYC began their efforts by soliciting direct feedback from older New York City residents through a series of town halls that were conducted in seven different languages and drew approximately 1500 older adults and their caregivers. ${ }^{76}$ In response to the findings of the assessments, in 2009, the City announced 59 initiatives across 13 city agencies to improve the quality of life for older adults. The city also appointed a Commission for an Age-Friendly NYC to engage private organizations in becoming more inclusive. Some of the results of the initiatives included: making streets safe for older adults to cross, installing over 1500 new benches throughout the city, using school buses to drive older people to supermarkets, installing safe, accessible bus stop shelters, and improving access to recreational and cultural activities. ${ }^{77}$

Age-Friendly NYC has a preventive approach at its core. If we create the right conditions, we can keep people independent and avoid or delay frailty. 


\section{The Aging Economy}

In her interview, Lindsay Goldman noted that business owners and policy makers must recognize that older adults are a large voting and consumer population. Supporting older individuals and creating inclusive cities and businesses is in the best the interests of everyone. From the vantage point of fiscal prudence, keeping people engaged and active slows the trajectory of illness and disability, which reduces the need for city services and social insurance programs.

\section{Multi-sectoral Partnerships}

The Age-Friendly NYC Commission members, appointed by the Mayor, represent sectors including architecture, libraries, technology, urban planning, education, local businesses, and resilience. The Commission also includes the presidents of all five boroughs, the speaker of the City Council, select Council members, and the commissioner of the Department of Aging. Through this multidisciplinary public and private partnership, the Commission works to influence planning, policy, and future initiatives. The Commission also develops toolkits in different languages that contain industry-specific age-friendly recommendations. ${ }^{78}$

An example of one of the public private partnerships that Lindsay described was a partnership with the Design for Aging Committee ${ }^{79}$ of the American Institute of Architects' New York Chapter. ${ }^{80}$ Age-Friendly NYC and the Department for the Aging worked with the Design for Aging Committee to produce an aging-in-place guide to educate building owners about low- and no-cost improvements to keep older residents healthy and safe and reduce falls risk. Lindsay expressed the need for the overarching concept of "age in everything" because health systems, city designs, and policies that are good for older community members are good for everyone.

Another program that builds age-inclusive communities designed by stakeholders to support social inclusion, purposeful living, and intergenerational connections is Ibasho. 
Our focus should be on what we can design to create opportunities for older adults to make a purposeful contribution to the world in the meaningful relationships with people of all ages. (Emi Kiyota)

\section{Emi Kiyota M.Arch. and Ph.D, Ibasho}

Emi Kiyota is an environmental gerontologist and the founder and president of Ibasho. ${ }^{81}$ She recently completed a Loeb Fellowship at Harvard University and will be participating in an Atlantic fellowship at the Global Brain Health Institute in the University of California San Francisco where she will be studying dementia-inclusive cities planning.

\section{Elder Resilience}

Ibasho is a Japanese term meaning, "whereabouts" but implying "a place where you feel at home being yourself." Ibasho is built on the belief that elders are a resource, not a burden. The Ibasho cafés serve as a source of connection and support for those most marginalized and each café functions as an evacuation center. Emi stressed that disasters impact older and disabled adults disproportionately. ${ }^{82,83,84,85}$ The first Ibasho café was built in 2013 as a form of resilience support in Ofunato, Japan, after the Great East Japan earthquake and tsunami that displaced 65,000 people. The next Ibasho café was built in Barangay Bagong Buhay, Ormoc City, Province of Leyte, Philippines in 2014 after Typhoon Yolanda. The Ibasho community members in Japan funded part of the project and visited the community to offer assistance and guidance. Emi mentioned that the café is changing the local perception of aging by being instrumental in the community recovery. The most recent Ibasho café was built in Kathmandu, Nepal, after the 7.8 magnitude earthquake of 2015 that affected more than 8000 people.

The café building serves as a tool to develop community capacity and give older residents the opportunity to learn and work together to solve the problem of social isolation. 


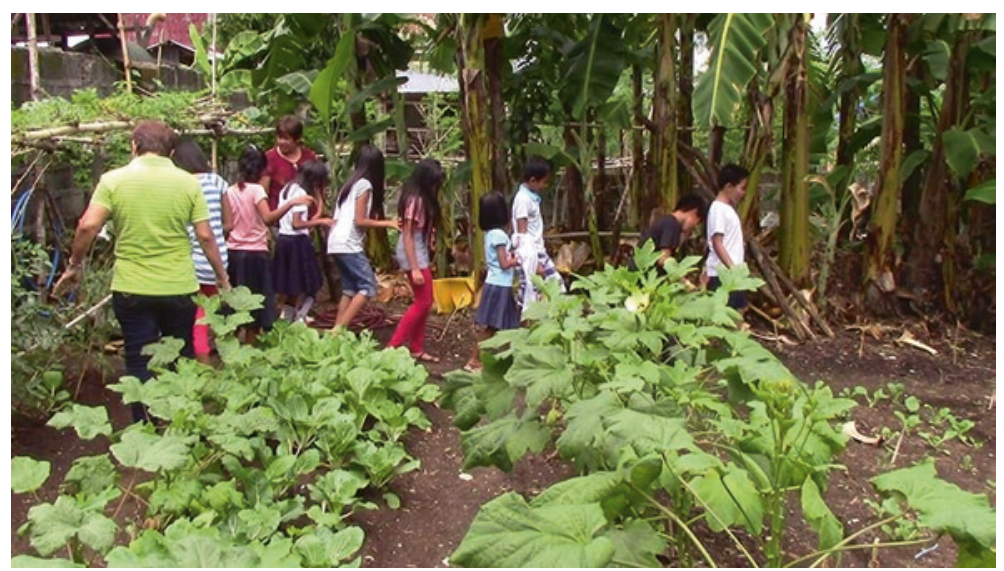

Ibasho Garden in the Philippines

\section{Bottom-Up Design and Operation}

The cafés are designed, built, and operated by the community members of all ages. Emi refers to this as a bottom-up approach that honors the wisdom of all of the community members. The cafés are culturally relevant self-sustaining community hubs that are made possible by coalitions of local community members of all ages, technical experts, government entities, and non-for-profit organizations.

Making lasting friendships in older age is not common and it is profoundly important.

Ibasho community members participate in programs together and are connected by a shared purpose. People of all levels of physical and cognitive abilities are encouraged to spend as much time in the cafés and participate in any community activates that they chose. The activities of each café are individual to their location and the community interest. Some projects include gardening and selling produce, running a noodle house, operating a tea house, growing flowers, selling crafts made by café members, and housing an internet café. Emi expressed the idea that making good friends in older age is not as easy as when we are young. She has 
witnessed many older adults working together and becoming good friends as a result. Some continue to visit friends after one has moved into a nursing home. They also look out for each other; if one member does not visit the café as usual, their friend will check on them.
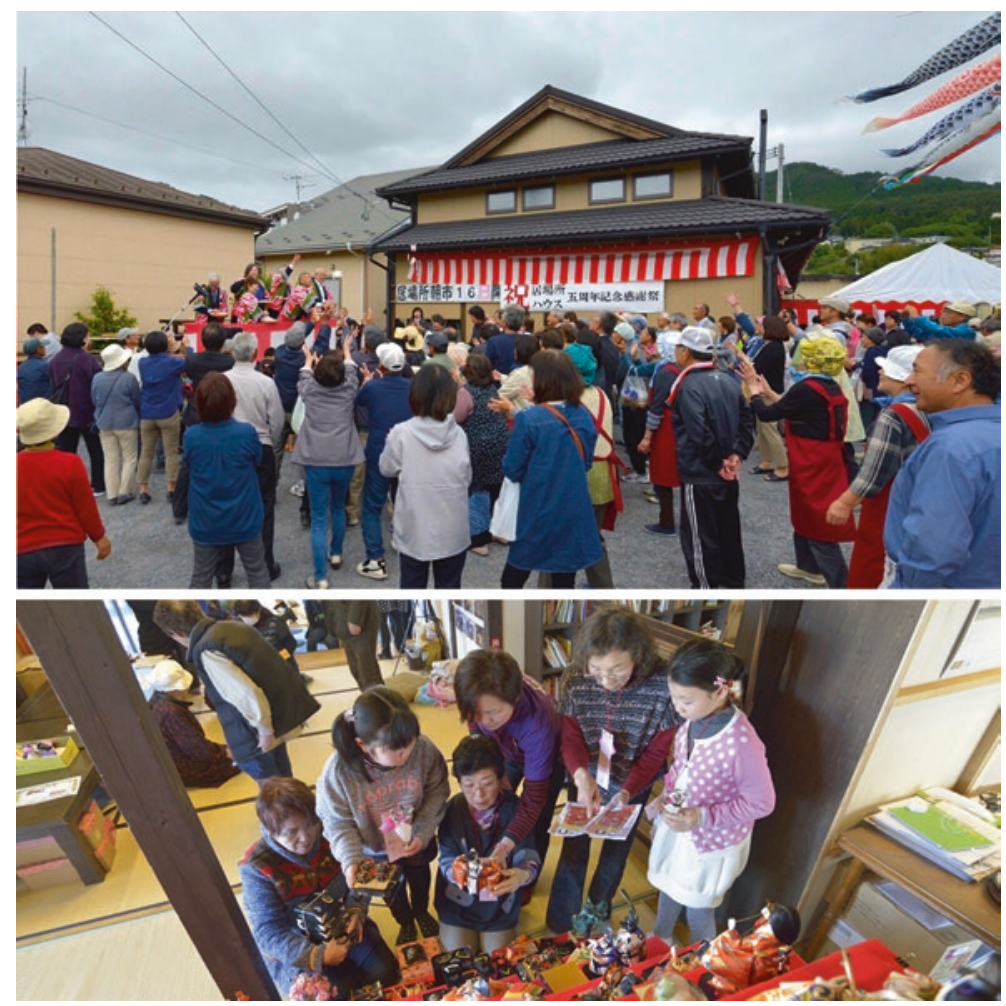

Ibasho Café, Japan, Five-Year Anniversary Celebration

Children are good for older people because older people are filled with the spirit of generativity.

\section{Intergenerational Connections}

Ibasho café members organize many programs that involve children. In some programs, the older residents act as grandparents and impart love and wisdom. Occasionally, the younger community members participate 
in the program design. In Nepal, the youth decided to teach the older residents how to read and write. This underlines the importance of involvement of all ages and the understanding that everyone can purposefully contribute to the community.

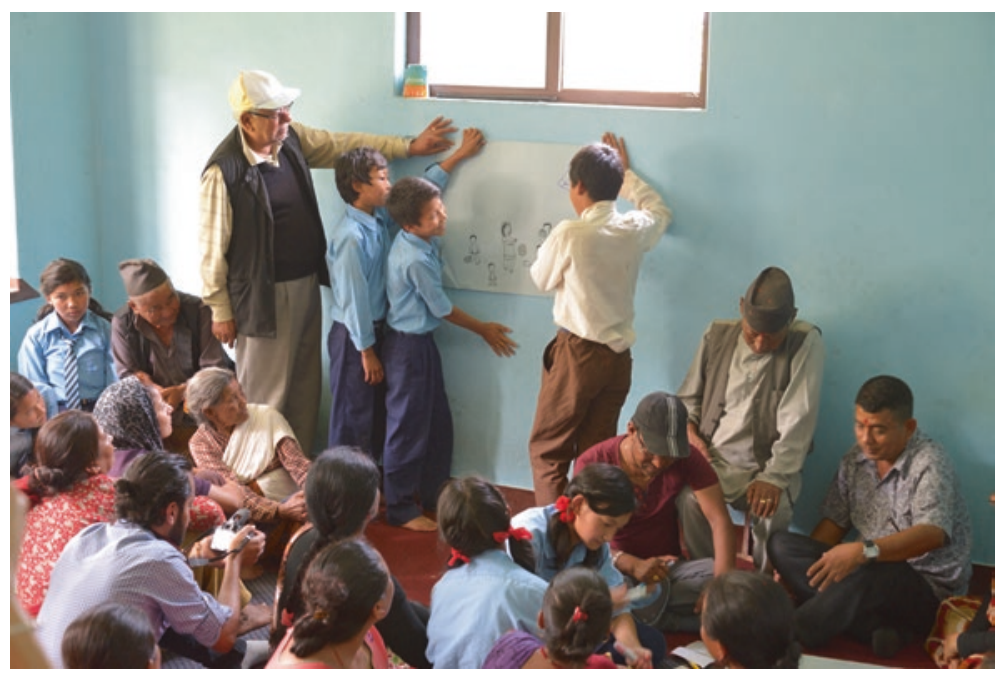

Ibasho Nepal Vision Workshop

Our goal is not to only create the building. Our goal is to change social perceptions about aging and the role of elders. We use the building as a tool to develop community capacity because older people have to learn to work together as a group to solve the problem of social isolation.

In June 2018, in collaboration with the World Bank and the Asian Development Bank, members of Ibasho Nepal, Japan, and the Philippines met in Ormoc, Philippines, for a peer-to-peer program to exchange learning and determine the provision of inputs. The participants also collaborated to document strategies and best practice. They also shared emerging lessons from implementation of Ibasho activities and research findings from the three countries with technical experts and development partners. The symposium presented opportunities for elders to build cross-cultural support networks. It also provided the space and incentive for technical experts to reimagine the role of elders when designing physical and social infrastructures. 


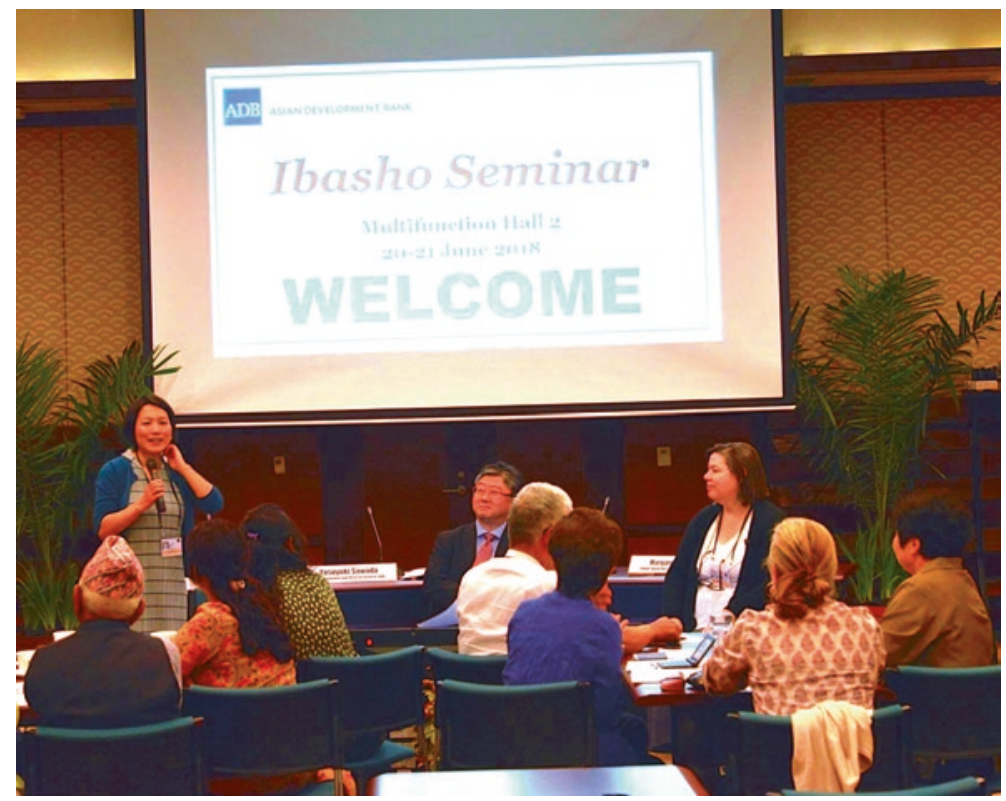

Emi Kiyota Opening the 2018 Peer-to-Peer Exchange Program

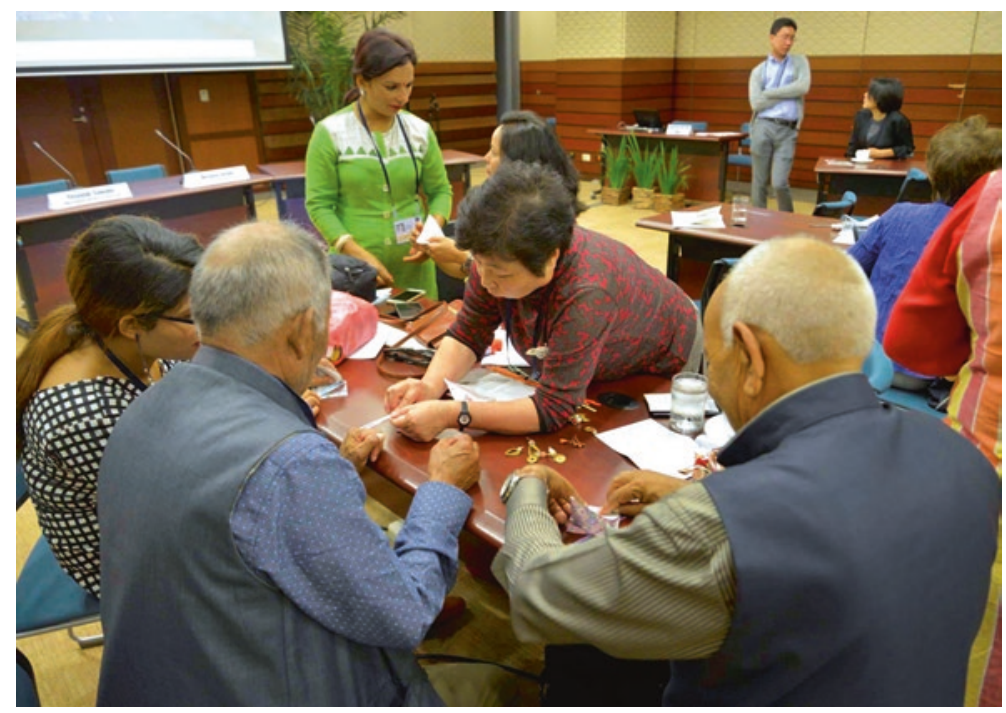

Ibasho Members from Nepal, Japan, and the Philippines Sharing their Skills and Knowledge 
Some of the most memorable quotes from the peer-to-peer exchange meeting include:

- "The beauty of Ibasho is that disaster brought us together and unleashed our potential to build the community that we have become." (Ibasho Nepal)

- "It was difficult to rise up and recover our life again. We lost properties, friends, family members. Ibasho played a huge part in helping them stand again and live a normal life." (Ibasho Japan)

- "We have to continue and move forward. We are grateful for Emi Kiyota and Ibasho for helping us not be left behind by transforming us to become productive members of the society. Respect towards the elders, especially from the younger generations in The Philippines, is fading. Because of Ibasho projects like recycling of plastics, we are proof that elders are also useful members of the society."

Emi hopes to broaden the idea of Ibasho cafés to Ibasho villages, where community members use existing community resources to create community hubs throughout the village. Examples Emi gave include building an internet café in an existing senior residence, making private libraries available to all, and using existing buildings to house community activities.

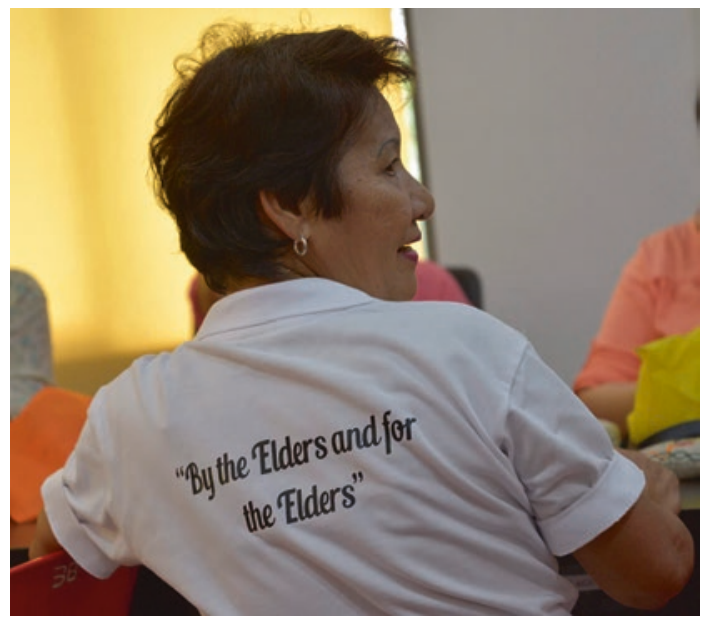

Annie Lambo Ibasho Philippines member talking about her experience of developing the Ibasho Philippines. The Ibasho Philippines Elders composed the quote printed on Annie's blouse 


\section{Timebanking}

Another example of using existing community resources to promote social inclusion is timebanking. ${ }^{86}$ Edgar Cahn founded the concept of timebanking in 1980 as a response to governmental policy that lessened support for social programs. ${ }^{87} \mathrm{He}$ is the author of two books on timebanking: Time Dollars: The New Currency that Enables Americans to Turn Their Hidden Resource-Time-Into Personal Security \& Community Renewal and No More Throw-Away People. Timebanks are an organized method for individuals to donate their time by exchanging skills or teaching to a community member and receive skills or teaching from the same or another community member in return. ${ }^{88}$ Timebanks are based on the theory of Co-Production ${ }^{89}$ where the person receiving will also be contributing, which creates equality among community members.

linkAges timebank cuts across social categories including income status, education, and ethnicity. Loneliness affects every demographic and social strata. (Dr. Paul Tang)

\section{Paul Tang, linkAges ${ }^{90}$}

At the time of his interview, Dr. Paul Tang was the Director of the David Druker Center for Health Systems Innovation. Today he is the Vice President and Chief Health Transformation Officer at IBM Watson Health.

The David Druker Center for Health Systems Innovation designs and implements programs to support community health and well-being that are based on the Center's core beliefs that:

- Health is more than healthcare;

- Each community member has the ability to contribute to the health of other community members; 
- It is imperative that health systems collaborate with communities to meet the individual needs of their patients. ${ }^{91}$

One of the programs of the David Druker Center for Health Systems Innovation is the linkAges timebank network that facilitates purposeful intergenerational connections and valuable social support systems within existing communities. The name, linkAges stands for linking across the ages.

We are enhancing the resilience of families and communities by increasing a sense of wellbeing and happiness in the community.

A multidisciplinary team of physicians, clinicians, an ethnographer, and administrators designed the linkAges timebank model. The ethnographer conducted a series of interviews with older adults to learn what prevented them from living life as fully as they wished. The two main barriers the interviews revealed were isolation and loneliness. One interviewee said, "As you age, your world dies before you do." That information was the inspiration for the linkAges timebanks.

The world goes around because people can and do share with other people who have needs or would like to enrich their lives by learning something new.

\section{Lifelong Learning}

Paul Tang mentioned that members in the linkAges communities exchange tasks such as organizational and housekeeping projects, skills sharing, and transportation. Most trades, however, are those for enrichment by learning a new skill or hobby such as technology or photography. 


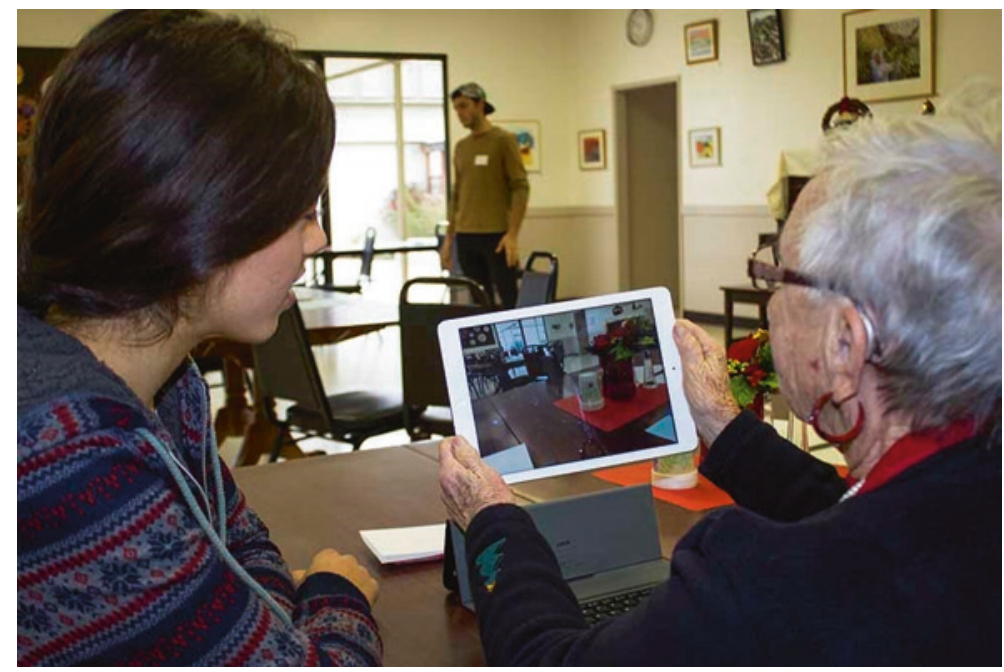

Technology instruction at linkAges timebank exchange

We are seeing the very cross-generational exchange and learning that you would like to see in a cultured society. We are rebuilding community.

\section{Intergenerational Connections}

The linkAges timebanks are comprised of all generations with one third over age 65, one third between 50 and 64, and one third younger than 50. Most of the exchanges for members over 50 occur with a younger community member.

Social services create a natural form of prevention.

\section{Upstream Health Prevention and Resilience}

Paul mentioned that the healthcare costs in the United States are high, while the quality outcomes rank last among developed nations. He believes that America can learn from other countries that invest in social 
services to prevent illness. The American system could be referred to as sick care as opposed to healthcare because the system is far more heavily based in treating illness and injury after it has occurred rather than preventing both. He asserts that healthcare only influences 10 percent of total health outcomes. ${ }^{92}$

Can we increase the percentage of those living healthy independent lives by one percent?

Because of the high cost of the "super utilizer" patients who are responsible for most of the healthcare spend in America, many insurers and providers are dedicated to building systems that serve this cohort better and at a lower cost. ${ }^{93}$ Paul noted that 5 percent of the population is responsible for 50 percent of the healthcare spend. Paul's unique perspective is focused further upstream on the 95 percent of the population, with an eye toward prevention. The David Druker Center for Health Systems Innovation has the goal of increasing the 95 percent to 96 and preventing 1 percent of the population from entering the "super utilizer" cohort. They believe that loneliness prevention and productive engagement in communities across the country has the potential to move that needle one tick. With a population of over 326 million, the value could be significant.

Providers should be compensated for improving the health status of the community they serve.

Paul believes that, due to the political nature surrounding social services in America, the private sector and healthcare providers bear the responsibility of community-based social service delivery. linkAges timebanks have the potential to be a benefit to any health system seeking to take on that mission. Today the linkAges timebanks are operational in the San Francisco Bay and Santa Cruz areas of Northern California. The Center plans to expand linkAges into Sacramento, California, next. The timebanks are open to individuals, organizations, and health systems.

The innovations for social inclusion for people of all ages and abilities in this chapter are a guiding light for how we must envision older adults 
in our community in the world — as assets of strength, insight, and purpose. We hope this chapter leaves the reader with a broader vision of health and well-being and the drive to advocate for social inclusion for people of all ages and abilities.

The full interviews referenced above can be found at this link: www. accessh.org/agingwell.

\section{Appendix: Indicators List: Essential Elements of an Elder Friendly Community}

\section{Percentage of People Age 65+ Who Report Their Community Is a Good Place to Live}

\section{Addresses Basic Needs}

- Affordable housing is available to community residents

1. Percentage of people age $65+$ who spend $>30 \% / \leq 30 \%$ of their income on housing

2. Percentage of people age $65+$ who want to remain in their current residence and are confident they will be able to afford to do so

- Housing is modified to accommodate mobility and safety

3. Percentage of householders age $65+$ in housing units with home modification needs

- The neighborhood is livable and safe

4. Percentage of people age $65+$ who feel safe/unsafe in their neighborhood

5. Percentage of people age $65+$ who report few/multiple problems in the neighborhood

6. Percentage of people age $65+$ who are satisfied with the neighborhood as a place to live 
- People have enough to eat

7. Percentage of people age $65+$ who report cutting the size of or skipping meals due to lack of money

- Assistance services are available and residents know how to access them

8. Percentage of people age $65+$ who do not know whom to call if they need information about services in their community

9. Percentage of people age $65+$ who are aware/unaware of selected services in their community

10. Percentage of people age $65+$ with adequate assistance in ADL and/or IADL activities

\section{Optimizes Physical and Mental Health and Well-Being}

- Community promotes and provides access to necessary and preventive health services

11. Rates of screening and vaccination for various conditions among people 65+

12. Percentage of people age $65+$ who thought they needed the help of a health care professional because they felt depressed or anxious and have not seen one (for those symptoms)

13. Percentage of people age $65+$ whose physical or mental health interfered with their activities in the past month

14. Percentage of people age $65+$ who report being in good to excellent health

- Opportunities for physical activity are available and used

15. Percentage of people age $65+$ who participate in regular physical exercise 
- Obstacles to use of necessary medical care are minimized

16. Percentage of people age $65+$ with a usual source of care

17. Percentage of people age $65+$ who failed to obtain needed medical care

18. Percentage of people age $65+$ who had problems paying for medical care

19. Percentage of people age $65+$ who had problems paying for prescription drugs

20. Percentage of people age $65+$ who had problems paying for dental care or eyeglasses

- Palliative care services are available and advertised

21. Percentage of people age $65+$ who know whether palliative care services are available

\section{Maximizes Independence for the Frail and Disabled}

- Transportation is accessible and affordable

22. Percentage of people age $65+$ who have access to public transportation

- The community service system enables people to live comfortably and safely at home

23. Percentage of people age $65+$ with adequate assistance in activities of daily living (ADL)

24. Percentage of people age $65+$ with adequate assistance in instrumental activities of daily living (IADL)

- Caregivers are mobilized to complement the formal service system

25. Percentage of people age $65+$ who provide help to the frail or disabled 
26. Percentage of people age $65+$ who get respite/relief from their caregiving activity

\section{Promotes Social and Civic Engagement}

- Residents maintain connections with friends and neighbors

27. Percentage of people age $65+$ who socialized with friends or neighbors in the past week

- Civic, cultural, religious, and recreational activities include older residents

28. Percentage of people age $65+$ who attended church, temple, or other in the past week

29. Percentage of people age $65+$ who attended movies, sports events, clubs, or group events in the past week

30. Percentage of people age 65+ who engaged in at least one social, religious, or cultural activity in the past week

- Opportunities for volunteer work are readily available

31. Percentage of people age $65+$ who participate in volunteer work

- Community residents help and trust each other

32. Percentage of people age $65+$ who live in "helping communities"

- Appropriate work is available to those who want it

33. Percentage of people age $65+$ who would like to be working for pay

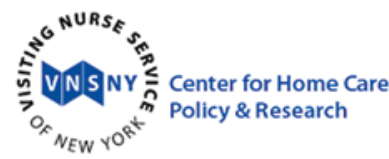




\section{Notes}

1. Arslantas, H., Adana, F., Ergin, F.A., Kayar, D. \& Acar, G. (2015). Loneliness in elderly people, associated factors and its correlation with quality of life: A field study from Western Turkey. Iranian Journal of Public Health, 44(1), 43-50.

2. Tian, Q. (2014). Intergeneration social support affects the subjective wellbeing of the elderly: Mediator roles of self-esteem and loneliness. Journal of Health Psychology, 21(6), 1137-1144.

3. Singh, K. \& Srivastava, S.K. (2014). Loneliness and quality of life among elderly people. Journal of Psychosocial Research, 9(1), 11-18.

4. Luo, Y., Hawkley, L.C., Waite, L.J, \& Cacioppo, J.T. (2012). Loneliness, health, and mortality in old age: A national longitudinal study. Social Science \& Medicine, 74(6), 907-914.

5. Steptoe, A., Shanker, A., Demakakos, P., \& Wardle, J. (2013). Social isolation, loneliness, and all-cause mortality in older men and women. Proceedings of the National Academy of Science, 110(15), 5797-5801.

6. Perissinotto, C.M., Cenzer, I.S., \& Covinsky, K.E. (2012). Loneliness in Older Persons. A predictor of functional decline and death. Archives of Internal Medicine, 172(14), 1078-1083.

7. World Health Organization (2002). Active aging. A policy framework. http://www.who.int/ageing/publications/active_ageing/en/. Accessed June 2017.

8. Holt-Lunstad, J., Smith, T.B., Baker, M., Harris, T., \& Stephenson, D. (2015). Loneliness and social isolation as risk factors for mortality. Sage Journals, 10(2), 227-237.

9. Mushtaq, R., Shoib, S., Shah, T., \& Mushtaq, S. (2014). Relationship between loneliness, psychiatric disorders and physical health. A review on the psychological aspects of loneliness. J Clin Diagn Res., 8(9), WE01-WE04.

10. McCall, W.V., \& Kintziger, K.W. (2014). Late life depression: A global problem with few resources. The Psychiatric Clinics of North America, 36(4), https://doi.org/10.1016/j.psc.2013.07.001.

11. Liu, L. Gou, Z., \& Zou, J. (2014). Social support mediates loneliness and depression in elderly people. Journal of Health Psychology, 21(5), 750-758.

12. Gan, P., Xie, Y., Duan, W., Deng, Q., \& Y, Xiuli (2015). Rumination and loneliness independently predict six-month later depression symp- 
toms among Chinese elderly in nursing homes. PLoS ONE, 10(9), $\mathrm{e} 0137176$.

13. Wong, N.M.L., Liu, H., Lin, C., Huang, C., Wai, Y., Lee, S., \& Lee, T.M.C. (2016). Loneliness in late-life depression: Structural and functional connectivity during affective processing. Psychological Medicine, 46(12), 2485-2499.

14. Alzheimer's Disease International (2012). World Alzheimer's report 2012. Overcoming the stigma of dementia. Pg. 9.

15. Thompson, E.H., \& Weaver, A.J. (2016). Making connections: The legacy of an intergenerational program. The Gerontologist, 56(5), 909-918.

16. Grefe, D. (2011). Combating ageism with narrative and intergroup contact: Possibilities of intergenerational connections. Pastoral Psychology, 60(99), 99-105.

17. Chippendale, T. \& Boltz, M. (2015). Living legends: Effectiveness of a program to enhance sense of purpose and meaning in life among community-dwelling older adults. The American Journal of Occupational Therapy, 69(4), 1-11.

18. Boyle, P.A., Barnes, L.L., Buchman, A.S., \& Bennett, D.A. (2009). Purpose in life is associated with mortality among community-dwelling older persons. Psychosom Med, 71(5), 574-579.

19. Boyle, P.A., Buchman, A.S., Wilson, R.S., Yu, L., Schneider, J.A., \& Bennett, D.A. (2002). Effect of purpose in life on the relation between Alzheimer disease pathologic changes on cognitive function in advanced age. Arch Gen Psychiatry, 69(5), 499-504.

20. Davy, J. (2012). Generativity: Contributing to others June enhance wellbeing. InvestigAge. http://www.investigage.com/2012/04/20/generativity-contributing-to-others-June-enhance-wellbeing/. Accessed June 2017.

21. Hafner, K (2016). Researchers confront an epidemic of loneliness. New York Times. https://www.nytimes.com/2016/09/06/health/lonlinessaging-healtheffects.html?_r=1. Accessed June 2017.

22. Bodewig, C., \& Hirshleifer, S. (2011). Advancing adult learning in Eastern Europe and Central Asia. Discussion paper, No. 1108. World Bank.

23. Holodny, E. (2016). This is a pretty worrying chart for China's demographic future. Business Insider. http://www.businessinsider.com/chinaworking-age-population-already-shrinking-2016-5. Accessed June 2017. 
24. Bagri, N.T. (2017). China's seniors are lining up to go back to school. Quartz. https://qz.com/978805/chinas-seniors-are-lining-up-to-go-backto-college/. Accessed June 2017.

25. Ibid.

26. Yiwen, C. (2017). Universities offer lifelong learning to China’s elderly. Sixth Tone. http://www.sixthtone.com/news/1840/universities-offer-lifelong-learning-to-chinas-elderly. Accessed June 2017.

27. www.aseniorcitizensguideforcollege.com. Accessed June 2017.

28. Manninen, J., Sgier, I., Fleige, M., Thöne-Geyer, B., Kil, M., Možina, E., Danihelková, H., Mallows, D., Duncan, S., Meriläinen, M., Diez, J., Sava, S., Javrh, P., Vrečer, N., Mihajlovic, D., Kecap, E., Zappaterra, P., Kornilow, A., Ebener, R., \& Operti, F. (2014). Benefits of lifelong learning in Europe: Main results of the BeLL-Project. Research report.

29. Fei You Community Services (2012). Lifelong learning among older adults in Singapore.

30. http://www.ohchr.org/EN/ProfessionalInterest/Pages/OlderPersons. aspx. Accessed June 2017.

31. The sharing of wisdom and knowledge to guide the next generations. Psychologist Erik Erikson coined the phrase.

32. http://www.beaconhillvillage.org. Accessed June 2017.

33. http://www.beaconhillvillage.org/content.aspx?page_id=22\&club_ id=332658\&module_id=77064. Accessed June 2017.

34. http://www.beaconhillvillage.org/content.aspx?page_id=2. Accessed June 2017.

35. https://www.genworth.com/about-us/industry-expertise/cost-of-care. html. Accessed June 2017.

36. https://www.seniorhomes.com/p/independent-living-costs/. Accessed June 2017.

37. Groer, A. (2017). Baby boomers join 'aging-at-home villages' for yoga, happy hour, cooking, classes and biking. Washington Post. https://www. washingtonpost.com/national/health-science/baby-boomers-join-agingat-home-villages-for-yoga-happy-hour-ladies-night-out-tech-class-andbiking/2017/05/04/7fdf5a78-1a2a-11e7-855e-4824bbb5d748_story. html?utm_term=.e701f9bb255e. Accessed June 2017.

38. www.vtvnetwork.org. Accessed June 2017.

39. http://www.vtvnetwork.org/content.aspx?page_id=1905\&club_ $\mathrm{id}=691012$. Accessed June 2017.

40. Brick, Y., \& Clarfield, A.M. (2007). "JED-ESHEL," a unique non-governmental organization dedicated to the elderly in Israel. Archives of Gerontology and Geriatrics, 44(3), 225-234. 
41. Strauss, I.E. (2016). The hot new millennial housing trend is a repeat of the middle ages. The Atlantic. https://www.theatlantic.com/business/ archive/2016/09/millennial-housing-communal-living-middleages $/ 501467 /$. Accessed June 2017.

42. www.cohousing.org. Accessed June 2017.

43. http://www.cohousing.org/node/3049. Accessed June 2017.

44. http://participateindesign.org/approach/what//. Accessed June 2017.

45. http://swansmarket.com. Accessed June 2017.

46. Accessed June 2017.

47. https://www.stjohnsliving.org/brickstone/gallery. Accessed June 2017.

48. https://www.stjohnsliving.org/uploads/files//meadows/pdf/ MeadowsJune.pdf. Accessed June 2017.

49. http://www.beatitudescampus.org/lifestyle/activities-events/. Accessed June 2017.

50. http://www.beatitudescampus.org. Accessed June 2017.

51. http://www.comfortmatters.org. Accessed June 2017.

52. http://www.lasellvillage.org. Accessed June 2017.

53. http://www.lasell.edu/academics/academic-centers/rosemary-b-fusscenter-for-research-on-aging-and-intergenerational-studies.html. Accessed June 2017.

54. https://www.youtube.com/watch?v=FHHhLD9nSU8. Accessed June 2017.

55. World Health Organization (2007). Global Age-Friendly Cities Guide. http://www.who.int/ageing/age_friendly_cities_guide/en/. Accessed June 2017.

56. http://successfulaging.milkeninstitute.org/Juneors-pledge/bcsa-Juneorspledge-with-intro-letter.pdf. Accessed June 2017.

57. Kubendran, S., \& Soll, L. (2007). Best cities for successful aging 2017. Milken Institute Center for the Future of Aging. http://www.milkeninstitute.org/publications/view/852. Accessed June 2017.

58. http://www.dhealthsummit.org/dont-tell-me-how-to-age/. Accessed June 2017.

59. https://apps.vnsny.org/advantage/whatis.html. Accessed June 2015.

60. https://www.mailman.columbia.edu/research/age-smart-employer. Accessed June 2017.

61. Greenwald, L., Copeland, C., \& VanDerhei, J. (2017). The 2017 retirement confidence survey: Many workers lack retirement confidence and feel stressed out about retirement preparations. Employee benefits research Institute. 
62. Siedle, E. (2013). The greatest retirement crisis in American history. Forbes. https://www.forbes.com/sites/edwardsiedle/2013/03/20/the-greatestretirement-crisis-in-american-history/\#c14762f55b6f. Accessed June 2017.

63. McGee, S. (2015). New study reminds us that Americans are woefully unprepared for retirement. The Guardian. https://www.theguardian. $\mathrm{com} / \mathrm{money} / 2015 / \mathrm{jun} / 07 /$ study-ramericans-retirement-401k-socialsecurity. Accessed June 2017.

64. Kirkham, E. (2016). 1 in 3 Americans has saved $\$ 0$ for retirement. Time. http://time.com/money/4258451/retirement-savings-survey/. Accessed June 2017.

65. Choe, S. (2017). Punching in past 65: Older-worker rate highest since 1962. The Associated Press. https://www.usatoday.com/story/money/ personalfinance/retirement/2017/05/10/punching-past-65-olderworker-rate-highest-since-1962/101447336/. Accessed June 2017.

66. Oxford Policy \& Human Development Initiative. http://www.ophi.org. $\mathrm{uk} /$ research/missing-dimensions/social-connectedness/social-isolation/. Accessed June 2017.

67. Butrica, B.A., Smith, K.E., \& Steuerle, C.E. (2006). Working for a good retirement. The Retirement Project. The Urban Institute. Pgs. 19-20.

68. Ibid.

69. Carnevale, A.P., Hanson, A.R., \& Gulish, A. (2013). Failure to launch. Structural shift and the new lost generation. The Generations Initiative. Georgetown University. Pg. 40.

70. Boston Consulting Group. The global workforce crisis: $\$ 10$ trillion at risk. https://www.bcgperspectives.com/content/articles/management_ two_speed_economy_public_sector_global_workforce_ crisis/?chapter=2. Accessed June 2017.

71. http://agesmartemployer.org. Accessed June 2017.

72. Butler, R.N. (1969). Age-ism: another form of bigotry. Gerontologist, 9(4), 243-246.

73. Richeson, J.A., \& Shelton, N. (2006). Psychological perspective on the stigmatization of older adults. In: National Research Council (US) Committee on Aging Frontiers in Social Psychology, Personality, and Adult Developmental Psychology; Carstensen LL, Hartel CR, editors. When I'm 64. Washington DC, National Academies Press.

74. https://www.exceedingexpectations.nyc. Accessed June 2017.

75. https://nyam.org/age-friendly-nyc/. Accessed May 2017. 
76. https://nyam.org/media/filer_public/f6/7f/f67fe2c7-f400-4060-8919081766131eda/agefriendlyfindingsreport.pdf. Accessed May 2017.

77. http://www.nyc.gov/html/dfta/downloads/pdf/age_friendly_report13. pdf. Accessed May 2017.

78. https://nyam.org/age-friendly-nyc/resources/tools-publications/tools/. Accessed May 2017.

79. https://network.aia.org/designforaging/home. Accessed May 2017.

80. https://main.aiany.org. Accessed May 2017.

81. http://www.ibasho.org/web/. Accessed June 2017.

82. Harvey, S.A. (2017). Natural disasters are especially hard on seniors. The Cornell Chronicle. Cornell University. http://news.cornell.edu/stories/2013/03/natural-disasters-are-especially-hard-seniors. Accessed June 2017.

83. Kulcsar, A. (2013). Older people disproportionately affected by Typhoon Haiyan. HelpAge International. http://www.helpage.org/newsroom/latest-news/older-people-disproportionately-affected-by-typhoon-haiyan/. Accessed June 2017.

84. Parry, W. (2013). Why disasters like Sandy hit the elderly hard. LiveScience. http://www.livescience.com/27752-natural-disasters-hitelderly-hard.html. Accessed June 2017.

85. CDC's Disaster Planning Goal: Protect Vulnerable Older Adults. https:// www.cdc.gov/aging/pdf/disaster_planning_goal.pdf. Accessed June 2017.

86. https://www.youtube.com/watch?v=D8R6VkqvsBY. Accessed June 2017.

87. http://timebanks.org. Accessed June 2017.

88. https://vimeo.com/110908351. Accessed June 2017.

89. http://www.scie.org.uk/publications/guides/guide51/what-is-coproduction/defining-coproduction.asp. Accessed June 2017.

90. https://community.linkages.org. Accessed June 2017.

91. https://innovation.pamf.org. Accessed June 2017.

92. Sederer, Lloyd (2013). Population health: Transforming healthcare to improve our health. Huffington Post. http://www.huffingtonpost.com/ lloyd-i-sederer-md/health-care_b_4455582.html. Accessed June 2015.

93. Robert Wood Johnson (2014). http://www.rwjf.org/en/library/collections/super-utilizers.html. Accessed June 2015. 
Open Access This chapter is licensed under the terms of the Creative Commons Attribution 4.0 International License (http://creativecommons.org/licenses/ by/4.0/), which permits use, sharing, adaptation, distribution and reproduction in any medium or format, as long as you give appropriate credit to the original author(s) and the source, provide a link to the Creative Commons licence and indicate if changes were made.

The images or other third party material in this chapter are included in the chapter's Creative Commons licence, unless indicated otherwise in a credit line to the material. If material is not included in the chapter's Creative Commons licence and your intended use is not permitted by statutory regulation or exceeds the permitted use, you will need to obtain permission directly from the copyright holder. 